\title{
Düzgün yıldız çokgenlerde çizgiler ve koordinatlar
}

\author{
Lines and coordinates in regular star polygons
}

\author{
Mehmet ARSLAN*1,a \\ ${ }^{1}$ Milli Ĕ̈itim Bakanlığı, Malatya Bilim ve Sanat Merkezi, 44100, Malatya
}

\begin{abstract}
• Geliş tarihi / Received: 01.01.2021 • • Düzeltilerek geliş tarihi / Received in revised form: 09.03.2021 • Kabul tarihi / Accepted: 13.03 .2021
\end{abstract}
\begin{abstract}
$\ddot{O} \mathbf{z}$
Bu çalışmada, geometrinin önemli konu başlıklarından biri olan ve on dördüncü yüzyıldan günümüze birçok eserde yer bulmuş düzgün yıldız çokgenler konusu ele alınmıştır. Konu ile ilgili bilinen tanım ve özelliklere, süreç sonunda önemli sayıda yeni tanım ve özellik eklenmiştir. Düzgün yıldız çokgenlerin temel mantığından hareketle, düzgün çokgenler kullanılarak bilinen çizim tekniğinden farklı yeni bir çizim tekniği geliştirilmiştir. Düzgün yıldız çokgenlerin köşe noktalarını birleştiren eş doğru parçaları oluşum çizgileri olarak adlandırılmış ve çalışma bu kapsam etrafinda ele alınmıştır. Oluşum çizgileri yatay eksenle meydana getirdikleri açılara göre dar ve geniş olarak sınıflandırılmış ve önemli sonuçlar elde edilmiştir. Düzgün yıldız çokgenler üzerinde dar ve geniş oluşum çizgilerinin yerleşim düzeninin açısal dizilimi ile dar ve geniş oluşum çizgi sayısı mod 4'e göre genelleştirilmiştir. Herhangi bir düzgün yıldız çokgen üzerinde oluşum çizgilerinin kesişmesiyle oluşan noktaların birleştiren çemberlere çember katmanları ve oluşum çizgilerinin kesişim noktalarına yıldız koordinatlar adı verilip özellikleri incelenmiştir. Herhangi bir düzgün yıldız çokgende yıldız koordinatların konumlarını şekil çizmeden dört adımda belirleyebileceğimiz bir yöntem geliştirilmiş ve uygulamalarla desteklenmiştir. Tüm yıldız çokgenler için yıldız koordinatların konumlarının çizime ihtiyaç duyulmaksızın belirlenebilmesi yeni çalışmalara zemin hazırlayacaktır. Kavramsal olarak tüm düzgün çokgenlerin aynı zamanda düzgün yıldız çokgenler olması konuya ayrı bir önem yüklemektedir.
\end{abstract}

Anahtar kelimeler: Dar açılı çizgi, Düzgün yıldız çokgenler, Geniş açılı çizgi, Oluşum çizgileri, Yıldız koordinatlar

\begin{abstract}
In this study, the subject of regular star polygons, which is one of the important topics of geometry and which has taken place in many works since the fourteenth century, is discussed. A significant number of new definitions and features were added at the end of the process to the known definitions and features related to the subject. Based on the basic logic of regular star polygons, a new drawing technique has been developed, which is different from the known drawing technique using regular polygons. Equivalent parts of regular star polygons connecting the corner points are called formation lines and the study is dealt with around this scope. The lines of formation are classified as acute and obtuse according to the angles they form with the horizontal axis and important results are obtained. The angular arrangement of the layout of acute and obtuse formation lines on regular star polygons and the number of acute and obtuse formation lines are generalized according to mode 4. The circles connecting the points formed by the intersection of the formation lines on any regular star polygon are called the circle layers and the intersection points of the formation lines are called star coordinates and their properties are examined. A method in which we can determine the position of the star coordinates in any regular star polygon in four steps without drawing shapes has been developed and supported by applications. The determination of the position of the star coordinates for all star polygons without the need for drawing will prepare the ground for new studies. Conceptually, the fact that all regular polygons are also regular star polygons puts a special emphasis on the subject.
\end{abstract}

Keywords: Acute angle line, Regular star polygons, Obtuse angle line, Formation lines, Star coordinates

\footnotetext{
*a Mehmet ARSLAN; marslan@gtu.edu.tr, Tel: (0505) 38449 41, orcid.org/0000-0003-0519-373X
} 


\section{Giriş}

Düzgün yıldız çokgenler geometrinin önemli bir araştırma konusudur. İlk olarak on dördüncü yüzy1lda Thomas Bradwardine "Geometria Speculativa" isimli çalışmasında yıldız çokgenlerden bahsetmiştir (Bradwardine, 1989). Daha sonra 1619 yilında Johannes Kepler "Harmonices Mundi" isimli çalışmasında bu konuda sistematik olarak ilerlemeler elde etmiştir (Kepler, 1997). Kepler düzgün çokgenin bir uyarlaması olarak yıldız çokgenleri tanımlamıştır (Coxeter, 1969). Harold S. M. Coxeter ve Robert S. Wilson tarafindan düzgün yıldız çokgenlerin tanım ve özellikleri üzerine çalışmalar yapılmıştır (Coxeter, 1974; Wilson, 2001).

Ayrıca düzgün yıldız çokgenlerin geometrik süsleme sanatında geniş bir uygulama alanına sahip olduğu bilinmektedir (Grunbaum ve Shephard, 1977; Mülayim, 1982; Khamjane ve Benslimane, 2018; Arslan ve Tuncel, 2019).

Tüm düzgün çokgenlerin aynı zamanda düzgün yıldız çokgen olması gerçeği konuyu çalışmaya değer kılmaktadır. Bu çalışmada, düzgün yıldız çokgenlerin tanımı, özelikleri ve oluşum çizgileri incelenecektir. İlk olarak bilinen tanım ve özellikler çerçevesinde önemli yeni tanımlar ve özellikler oluşturulmuştur. Düzgün y1ldız çokgen temel tanımından yola çıkılarak bilinen çizim tekniklerinden farklı bir çizim tekniği geliştirilmiştir. Düzgün yıldız çokgenler oluşum çizgileri kapsamında ele alınmış, oluşum çizgilerinin yatay eksenle meydana getirdikleri açılara göre sınıflandırılmıştır. Düzgün yıldız çokgenleri oluşturan oluşum çizgileri yatay eksenle oluşturdukları açılara göre "dar açılı çizgi" ve "geniş açılı çizgi" şeklinde adlandırılıp önemli sonuçlar elde edilmiştir. Düzgün yıldız çokgen üzerinde dar ve geniş oluşum çizgilerinin yerleşim düzeni ile dar ve geniş oluşum çizgi sayısı mod 4'e göre genelleştirilmiştir. Herhangi bir $\{n / k\}$ düzgün yıldız çokgeni üzerinde oluşum çizgilerinin kesişmesiyle oluşan noktalardan geçen çemberlere "çember katmanları" ve oluşum çizgilerinin kesişim noktalarına "yıldız koordinatlar" ad1 verilip özellikleri incelenmiştir. Herhangi bir $\{n / k\}$ düzgün yıldız çokgeninde oluşum çizgilerinin açılarına göre yerleşim düzenini ve yıldız koordinatlarının konumlarını şekil çizmeden belirleyebileceğimiz algoritmalar geliştirilmesi amaçlanmıştır.

\section{Materyal ve metot}

$\mathrm{Bu}$ çalı̧̧mada, düzgün yıldız çokgenler ile ilgili bilinen tanım ve özellikler incelenerek yeni sonuçlara ulaşılmıştır. Çalışma sürecinde çizimler Cabri II Plus geometri programı kullanılarak elde edilmiştir.

Tanım $2.1 k \geq 1, n \geq 3$ ve $k, n \in N$ olmak üzere bir daire üzerinde eşit aralıklı $n$ nokta alıp herhangi bir noktadan itibaren her $k$. noktasını eș doğru parçaları ile bağlayarak oluşturulan şekle düzgün yıldız çokgen denir (Coxeter, 1974; Wilson, 2001). $\mathrm{Bu}$ çalışmada, her $k$. noktasının bağlı olduğu $n$ köşeli düzgün yıldız çokgen $\{n / k\}$ Schläfli sembolü ile ifade edilecektir.

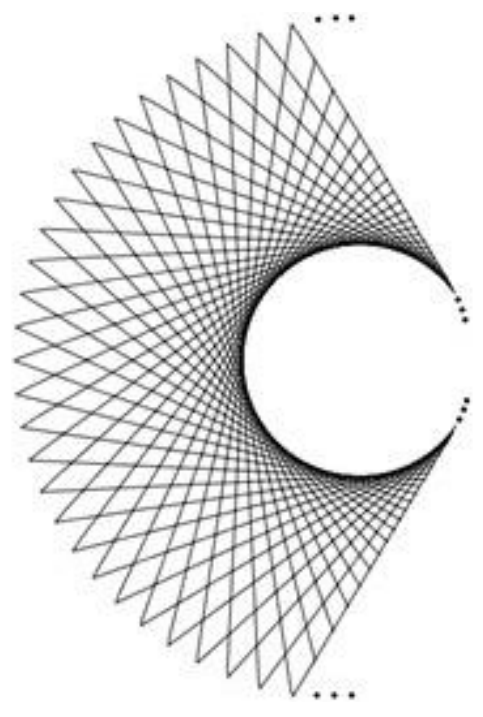

Şekil 1. $\{n / k\}$ Düzgün yıldız çokgeni

\section{Bulgular ve tartışma}

$\{n / k\}$ düzgün yıldız çokgenler, elle ya da çalışmamızda kullandığımız Cabri II Plus geometri programı ve benzer programlarda Tanım 2.1'de ifade edildiği şekilde bir daire üzerinde eşit aralıklı $n$ nokta alınıp herhangi bir noktadan itibaren her $k$. noktasını eş doğru parçaları ile bağlayarak oluşturulmaktadır. Burada düzgün yıldız çokgenler için farklı bir çizim tekniği verilecektir.

Öncelikle eş $n$ tane doğru parçası $\left(\frac{360}{n}\right)^{o}$ açıyla herhangi bir düzgün $n$-genin her bir kenarının üzerine, bir ucu bu kenarın orta noktasına gelecek şekilde yerleştirilir. Bu eş doğru parçaları kendi uzunlukları kadar ters yönde uzatılarak $\{n / k\}$ düzgün y1ldız çokgeni ve seçilen $n$ için $\max \{k\}$ ya kadar tüm düzgün yıldız çokgenler elde edilir.

$\mathrm{Bu}$ çizim tekniğinde daire üzerinde eşit aralıklı noktalar oluşturulması gerekmemektedir. Özellikle 
elle düzgün yıldız çokgenler çizilirken yeni çizim tekniği kolaylık sağlayacak ve geometri programlarına da eklenebilecektir. Ayrıca çizim yapılırken düzgün $n$-genin her bir kenarına eş doğrular yerleştirildiğinde $\left(\frac{360}{n}\right)^{o}$ lik açılar kendiliğinden oluşacaktır.
Şekil 2'de bir 17-gen için 17 tane eş doğru parçası $\left(\frac{360}{17}\right)^{\circ}$ açıyla 17 -genin her bir kenarına yerleştirilmiştir. Daha sonra kenarların orta noktasına yerleştirilen eş doğru parçaları kendi uzunlukları kadar ters yönde uzatılmıştır. $\mathrm{Bu}$ şekilde $\{17 / 8\}$ düzgün yıldız çokgeni elde edilmiştir. $\{17 / 8\}$ düzgün yıldız çokgeni içerisinde iç içe 7 tane düzgün yıldız çokgen bulunmaktadır.
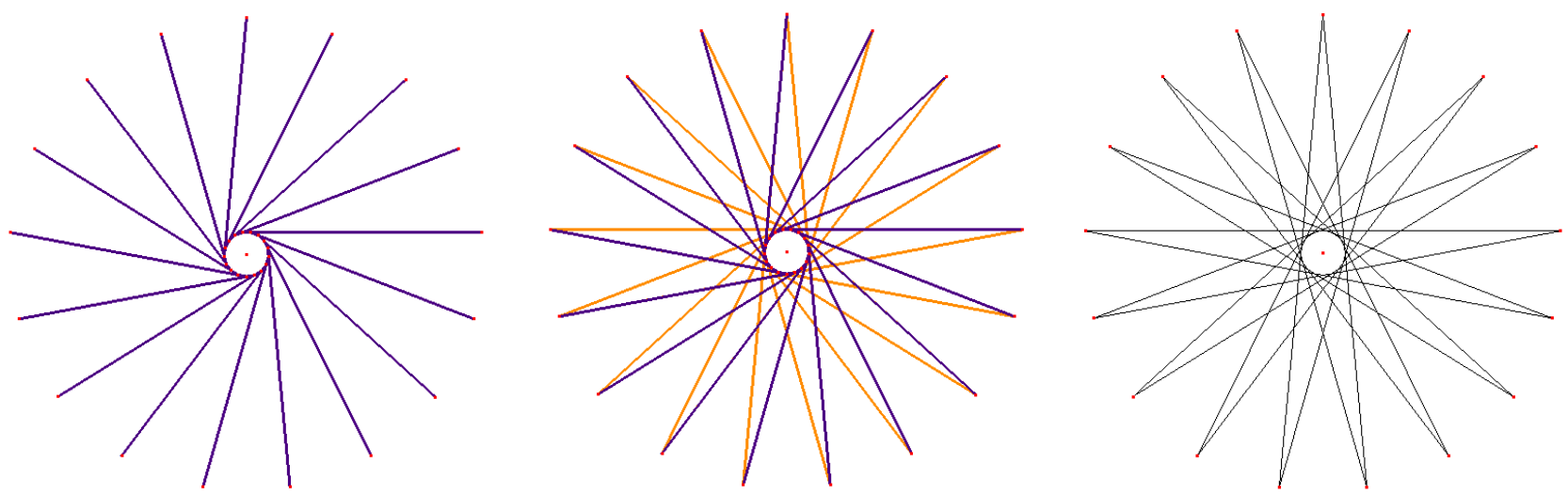

Şekil 2. Eş doğru parçaları ile $\{17 / 8\}$ düzgün yıldız çokgen oluşumu

3.1 Çember katmanları, oluşum çizgileri ve yıldız koordinatlar

\subsection{1 Çember katmanları}

Tanım 3.1 Herhangi bir $\{n / k\}$ düzgün yıldız çokgeni üzerinde köşe noktalarından geçen bir çember ile birlikte merkeze doğru oluşum çizgilerinin kesişmesiyle oluşan noktalardan geçen toplam $k$ tane çember çizebiliriz. Çizilen bu çemberlere düzgün yıldız çokgenin çember katmanları adı verilir.

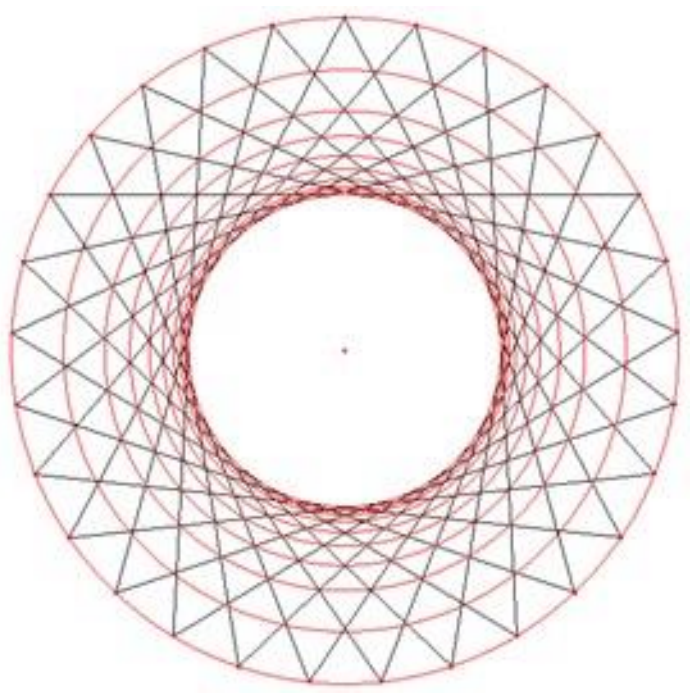

Şekil 3. $\{29 / 10\}$ düzgün y1ldız çokgeninde çember katmanları

\subsubsection{Oluşum çizgisi tanımı ve analizi}

Tanım $3.2 k \geq 1, n \geq 3$ ve $k, n \in N$ olmak üzere bir $\{n / k\}$ düzgün yıldız çokgeninde köşe noktalarını birleştiren eş doğru parçalarına oluşum çizgisi denir. Bir $\{n / k\}$ düzgün yıldız çokgende $n$ tane oluşum çizgisi bulunur.

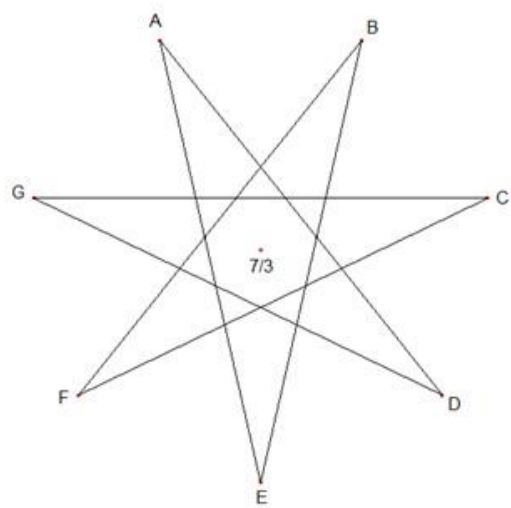

Şekil 4. $\{7 / 3\}$ düzgün yıldız çokgeninde oluşum çizgileri

Şekil 4'te verilen $\{7 / 3\}$ düzgün yıldız çokgeninde $|A E|=|A D|=|B F|=|B E|=|C G|=|C F|=|D G|$ şeklinde yedi tane oluşum çizgisi vardır.

Bir $\{n / k\}$ düzgün yıldız çokgeninde $n$ toplam köşe sayısı ve $k$ ise Şekil 5 'te mavi renkte vurgulanmış oluşum çizgisinin bağlandığı noktanın işaretli noktadan sonraki sıra sayısıdır. $k$ tüm oluşum çizgilerinden aynı yöntemle belirlenebilir. 


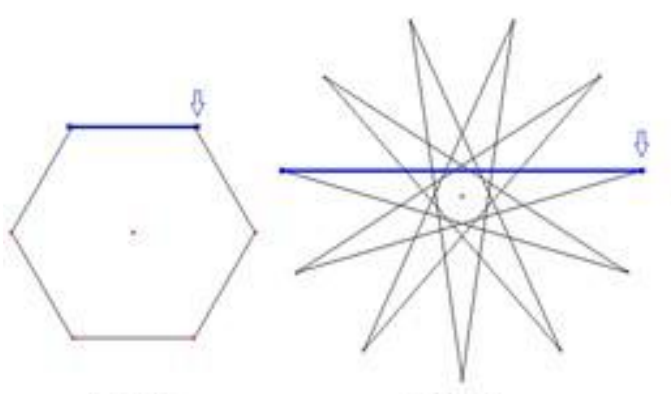

$\{6 / 1\}$

$\{11 / 5\}$

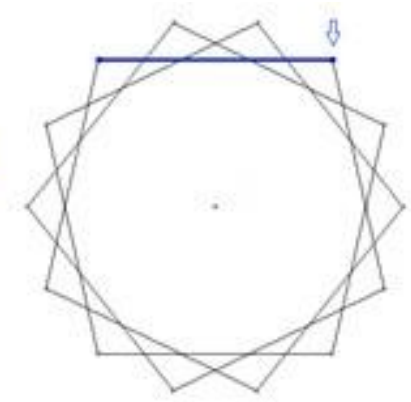

$\{14 / 3\}$

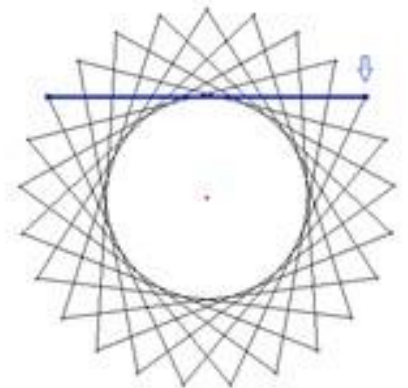

$\{25 / 8\}$

Şekil 5. Düzgün yıldız çokgenlerde $n$ ve $k$ tespiti

\subsubsection{Oluşum çizgilerinin sinıflandırılması}

Tanım 3.3 Düzgün yıldız çokgenleri oluşturan oluşum çizgilerine yatay eksenle oluşturdukları açılar [0,90) aralığında ise "dar açılı çizgi”,
$[90,180)$ aralığında ise "geniş açılı çizgi” denir.

Şekil 6'da dar açılı çizgiler mavi renk (en solda) ile ve geniş açılı çizgiler (en sağda) kırmızı renk ile gösterilmiştir.
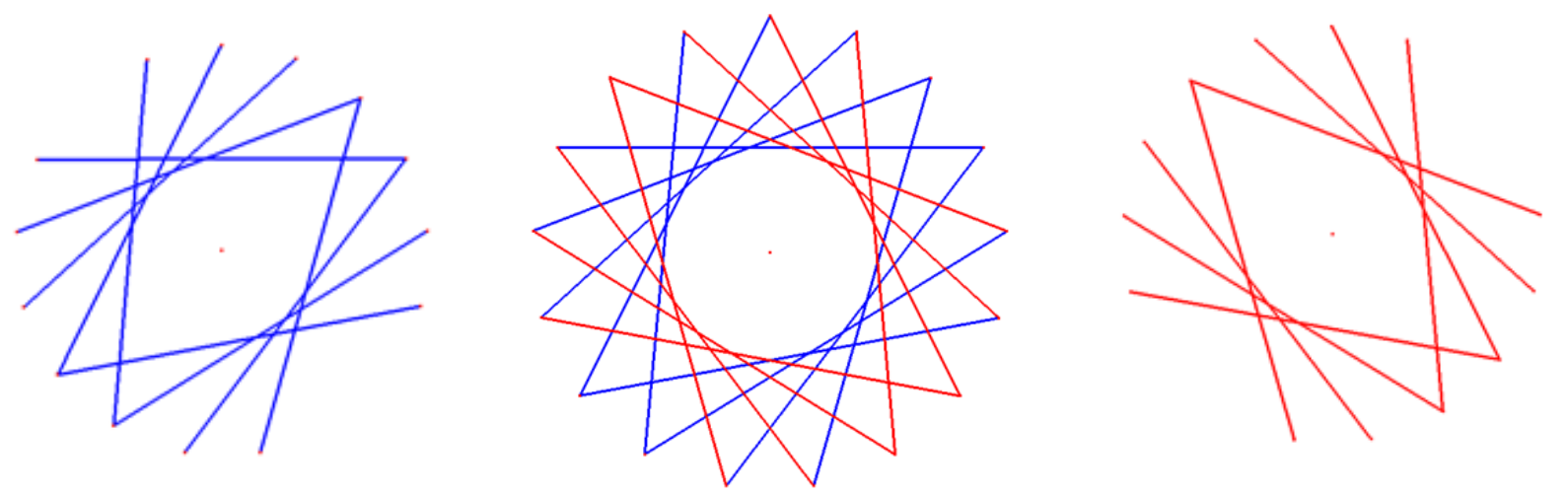

Şekil 6. $\{17 / 6\}$ düzgün yıldız çokgeninde dar açılı ve geniş açılı çizgiler

\subsubsection{Oluşum çizgilerinin sayısı ve yerleşim düzeni}

$k \geq 1, n \geq 3$ ve $k, n \in N$ olmak üzere herhangi bir $\{n / k\}$ düzgün yıldız çokgeninde üst bölgede yatay olarak belirlenen oluşum çizgisine birinci dar açılı çizgi $\left(d_{1}\right)$ denir. Saat yönünün tersinde düzgün yıldız çokgen oluşum mantığına uygun olarak sırasıyla köşe noktalarını sonraki $k$. noktaya bağlayan eş doğru parçaları, yatay eksenle oluşturdukları açıların dar ya da geniş oluşlarına göre $d_{1}, d_{2}, d_{3}, \ldots$ ve $g_{1}, g_{2}, g_{3}, \ldots$ şeklinde isimlendirilir.

$\mathrm{Bu}$ isimlendirme genelleştirilerek Tablo 1'de gösterilmiş ve ayrıca düzgün yıldız çokgen oluşum çizgilerinin yatay eksenle oluşturdukları açıların dar ya da geniş oluşlarına göre sınıflandırılması da verilmiştir. Tablo 1'de $n$ büyüdükçe dört kanaldan ayrı kurallarla oluşum çizgilerinin dizilmekte olduğu görülmüştür. $\mathrm{Bu}$ kurallarla şekil oluşturmadan herhangi bir $\{n / k\}$ düzgün yıldız çokgeninde oluşum çizgilerinin dizilimi elde edilir.

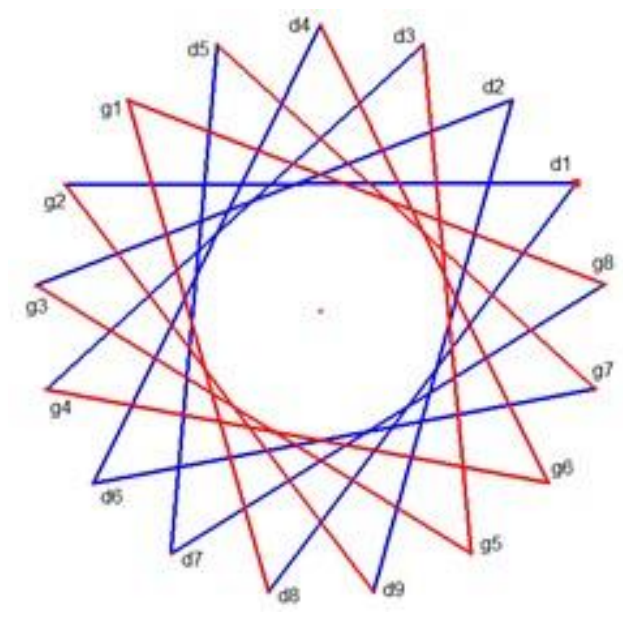

Şekil 7. $\{17 / 6\}$ düzgün yıldız çokgeninde oluşum çizgilerinin isimlendirilmesi 
Tablo 1. $\{n / k\}$ düzgün y1ldız çokgeninde dar ve geniş oluşum çizgilerinin açısal dizilimi




Tablo 1 'den $k \geq 1, n \geq 3$ ve $k, m, n \in N$ olmak üzere herhangi bir $\{n / k\}$ düzgün yıldız çokgenini oluşturan oluşum çizgilerinin sayısını, yatay eksenle oluşturdukları açıların dar ya da geniş oluşlarına göre aşağıdaki gibi elde ederiz;

- $n=4 m$ ise $2 m$ tane geniş açıll, $2 m$ tane dar aç1l çizgi mevcuttur,

- $n=4 m+1$ ise $2 m$ tane geniş açıll, $2 m+1$ tane dar aç1lı çizgi mevcuttur,

- $n=4 m+2$ ise $2 m$ tane geniş aç11, $2 m+2$ tane dar açılı çizgi mevcuttur,

- $n=4 m+3$ ise $2 m+1$ tane geniş açıll, $2 m+2$ tane dar açılı çizgi mevcuttur.
Herhangi bir $\{n / k\}$ düzgün yıldız çokgeni için dar ve geniş oluşum çizgi sayısının genelleştirilmesi Tablo 2'de gösterilmiştir. Tablodan herhangi bir $\{n / k\}$ düzgün yıldız çokgeninde dar ve geniş oluşum çizgi sayısını dar ve geniş sütunlarında belirlerken $n$ dörde bölünür. Kalan 0 ise her sütun $\frac{n}{4}$ sayıda olur. Kalan 1 ise ilk sütun $\frac{n}{4}+1$ sayıda, diğer üç sütun $\frac{n}{4}$ sayıda olur. Kalan 2 ise birinci ve üçüncü sütun $\frac{n}{4}+1$ sayıda, diğer iki sütun $\frac{n}{4}$ sayıda olur. Kalan 3 ise ilk üç sütun $\frac{n}{4}+1$ sayıda, son sütun $\frac{n}{4}$ sayıda elde edilir.

Tablo 2. $\{n / k\}$ düzgün yıldız çokgeninde dar ve geniş oluşum çizgi sayıları

\begin{tabular}{|c|c|c|c|c|}
\hline$\{n / k\}$ & Dar & Geniş & Dar & Geniş \\
\hline$\{3 / k\}$ & 1 & 1 & 1 & \\
\hline$\{4 / k\}$ & 1 & 1 & 1 & 1 \\
\hline$\{5 / k\}$ & 2 & 1 & 1 & 1 \\
\hline$\{6 / k\}$ & 2 & 1 & 2 & 1 \\
\hline$\{7 / k\}$ & 2 & 2 & 2 & 1 \\
\hline$\{8 / k\}$ & 2 & 2 & 2 & 2 \\
\hline$\{9 / k\}$ & 3 & 2 & 2 & 2 \\
\hline$\{10 / k\}$ & 3 & 2 & 3 & 2 \\
\hline$\{11 / k\}$ & 3 & 3 & 3 & 2 \\
\hline$\{12 / k\}$ & 3 & 3 & 3 & 3 \\
\hline$\{13 / k\}$ & 4 & 3 & 3 & 3 \\
\hline$\{14 / k\}$ & 4 & 3 & 4 & 3 \\
\hline$\{15 / k\}$ & 4 & 4 & 4 & 3 \\
\hline$\{16 / k\}$ & 4 & 4 & 4 & 4 \\
\hline$\{17 / k\}$ & 5 & 4 & 4 & 4 \\
\hline$\{18 / k\}$ & 5 & 4 & 5 & 4 \\
\hline$\{19 / k\}$ & 5 & 5 & 5 & 4 \\
\hline$\{20 / k\}$ & 5 & 5 & 5 & 5 \\
\hline$\{21 / k\}$ & 6 & 5 & 5 & 5 \\
\hline$\{22 / k\}$ & 6 & 5 & 6 & 5 \\
\hline$\{23 / k\}$ & 6 & 6 & 6 & 5 \\
\hline & $\ldots$ & $\cdots$ & $\ldots$ & $\ldots$ \\
\hline$\{(4 m) / k\}$ & $m$ & $m$ & $m$ & $m$ \\
\hline$\{(4 m+1) / k\}$ & $\boldsymbol{m}+1$ & $m$ & $m$ & $m$ \\
\hline$\{(4 m+2) / k\}$ & $\boldsymbol{m}+1$ & $m$ & $\boldsymbol{m}+1$ & $m$ \\
\hline$\{(4 m+3) / k\}$ & $\boldsymbol{m}+1$ & $\boldsymbol{m}+1$ & $\boldsymbol{m}+1$ & $m$ \\
\hline$\ldots$ & $\cdots$ & $\cdots$ & $\cdots$ & $\cdots$ \\
\hline \multicolumn{5}{|c|}{$n=(4 m) \geq 4, \quad n=(4 m+1) \geq 5, \quad n=(4 m+2) \geq 6, \quad n=(4 m+3) \geq 3$} \\
\hline
\end{tabular}




\subsubsection{Ylldız koordinatlar}

Burada, oluşum çizgilerinin kesişim noktalarına "yıldız koordinatlar" adı verilerek genel belirleme kuralları ve özellikleri elde edilecektir.

Tanım $3.4 k \geq 1, n \geq 3$ ve $k, m, n \in N$ olmak üzere herhangi bir $\{n / k\}$ düzgün yıldız çokgeninde $n$ tane oluşum çizgisinin kesişmesi ile oluşan $n k$ sayıda noktayı

- $n=4 m$ ise $X=\{1,2, \ldots, 2 m\}$ ve

$$
Y=\{1,2, \ldots, 2 m\}
$$

- $n=4 m+1$ ise $X=\{1,2, \ldots, 2 m+1\}$ ve

$$
Y=\{1,2, \ldots, 2 m\}
$$

- $n=4 m+2$ ise $X=\{1,2, \ldots, 2 m+2\}$ ve

$$
Y=\{1,2, \ldots, 2 m\}
$$

- $n=4 m+3$ ise $X=\{1,2, \ldots, 2 m+2\}$ ve

$$
Y=\{1,2, \ldots, 2 m+1\}
$$

biçiminde parçalayabiliriz. $a, b, c \in X, d, e, f \in Y$ olmak üzere

$$
\left(d_{a}, d_{b}\right),\left(d_{c}, g_{d}\right),\left(g_{e}, g_{f}\right)
$$

noktalarından her birine "yıldız koordinat" denir. Burada, $d_{a}: a$.dar açılı doğruyu ve $g_{d}: d$. geniş açılı doğruyu belirtsin. Burada $\left(d_{a}, d_{b}\right)$ ise $d_{a}$ ve $d_{b}$ doğrularının kesişim noktasıdır. $\left(d_{a}, d_{b}\right)$ ve $\left(g_{e}, g_{f}\right)$ yıldiz koordinatlarında bir doğru kendisi ile bir noktada kesişemeyeceği için $a \neq b$ ve $e \neq f$ olmak zorundadır. Yildız koordinatlarda doğruların biri dar açılı diğeri geniş açılı ise, sıralı ikili de her zaman ilk terim dar açılı doğruları ikinci terim geniş açılı doğruları ifade etmektedir.

Herhangi bir $\{n / k\}$ düzgün yıldız çokgeninde yıldız koordinatları belirlemek için aşağıdaki adımlar takip edilir:

1. Adım. Herhangi bir çember katmanı, $j .(j=$ $1,2, \ldots, k)$ belirlenir.

2. Adım. Yıldız koordinatlar belirlenirken iki satırlı ya da sütunlu bir tablo oluşturulur.
3. Adım. $\{n / k\}$ düzgün yıldız çokgenin oluşum çizgilerinin açısal dizilim kurallarına bakılarak tablonun birinci satırı ya da sütunu elde edilir.

4. Adım. Birinci satır ya da sütundaki dizilimlerden ikinci satırı ya da sütunu yazarken sondan itibaren $j$ adım geri gidilir. Elde ettiğimiz yeni diziliminin ilk elemanı birinci satırdaki ya da sütundaki $d_{1}$ ile eşleştirilip sırasıyla devam edilir. $\mathrm{Bu}$ şekilde $j$. katmandaki tüm yıldız koordinatlar elde edilir.

Örnek 3.1 Şekil 7'de verilen $\{17 / 6\}$ düzgün yıldız çokgeni üzerinde 4 . katmanda bulunan tüm yıldız koordinatları elde edelim. Tablo 1'de verilen açısal dizilimlerden birinci sütunu, sondan itibaren 4

\begin{tabular}{|c|c|c|c|}
\hline & \multicolumn{2}{|c|}{$17 / 6$} & $\begin{array}{c}\text { Yildiz } \\
\text { koordinatlar }\end{array}$ \\
\hline & $d_{1}$ & $g_{5}$ & $\left(d_{1}, g_{5}\right)$ \\
\hline & $d_{2}$ & $g_{6}$ & $\left(d_{2}, g_{6}\right)$ \\
\hline & $d_{3}$ & $g_{7}$ & $\left(d_{3}, g_{7}\right)$ \\
\hline & $d_{4}$ & $g_{8}$ & $\left(d_{4}, g_{8}\right)$ \\
\hline & $d_{5}$ & $d_{1}$ & $\left(d_{5}, \mathrm{~d}_{1}\right)$ \\
\hline & $g_{1}$ & $d_{2}$ & $\left(d_{2}, g_{1}\right)$ \\
\hline & $g_{2}$ & $d_{3}$ & $\left(d_{3}, g_{2}\right)$ \\
\hline & $g_{3}$ & $d_{4}$ & $\left(d_{4}, g_{3}\right)$ \\
\hline & $g_{4}$ & $d_{5}$ & $\left(d_{5}, g_{4}\right)$ \\
\hline & $d_{6}$ & $g_{1}$ & $\left(d_{6}, g_{1}\right)$ \\
\hline & $d_{7}$ & $g_{2}$ & $\left(d_{7}, g_{2}\right)$ \\
\hline & $d_{8}$ & $g_{3}$ & $\left(d_{8}, g_{3}\right)$ \\
\hline & $d_{9}$ & $g_{4}$ & $\left(d_{9}, g_{4}\right)$ \\
\hline$\Uparrow$ & $g_{5}$ & $d_{6}$ & $\left(d_{6}, g_{5}\right)$ \\
\hline$\Uparrow$ & $g_{6}$ & $d_{7}$ & $\left(d_{7}, g_{6}\right)$ \\
\hline$\Uparrow$ & $g_{7}$ & $d_{8}$ & $\left(d_{8}, g_{7}\right)$ \\
\hline$\Uparrow$ & $g_{8}$ & $d_{9}$ & $\left(d_{9}, g_{8}\right)$ \\
\hline
\end{tabular}
adım geri giderek ikinci sütunu ve üçüncü sütunda yıldız koordinatları Tablo 3'deki gibi elde ederiz.

Tablo 3. $\{17 / 6\}$ düzgün yıldız çokgeninde 4 . katman üzerindeki yıldız koordinatlar

Örnek 3.2 $\{27 / 8\}$ düzgün yıldız çokgeninde 6 . ve 5. katmandaki yıldız koordinatları bulalım.

$\{27 / 8\}$ düzgün yıldız çokgeninde dar ve geniş oluşum çizgilerini çizim yapmadan, Tablo 1 ve Tablo 2 'de elde ettiğimiz algoritmaları kullanarak bulabiliriz;

$\{(4 m+3) / k\} \Rightarrow d_{1} d_{2} \ldots d_{m+1} g_{1} g_{2} \ldots g_{m+1} d_{m+2} d_{m+3} \ldots d_{2 m+1} g_{m+2} g_{m+3} \ldots g_{2 m+1}$ 
6. çember katmanındaki yıldız koordinatlar;

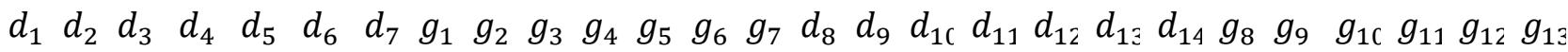

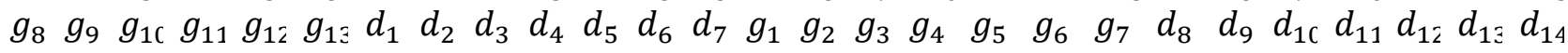

$$
\begin{aligned}
\{27 / 8\} \rightarrow & \left(d_{1}, g_{8}\right),\left(d_{2}, g_{9}\right),\left(d_{3}, g_{10}\right),\left(d_{4}, g_{11}\right),\left(d_{5}, g_{12}\right),\left(d_{6}, g_{13}\right),\left(d_{7}, d_{1}\right), \\
& \left(d_{2}, g_{1}\right),\left(d_{3}, g_{2}\right),\left(d_{4}, g_{3}\right),\left(d_{5}, g_{4}\right),\left(d_{6}, g_{5}\right),\left(d_{7}, g_{6}\right),\left(g_{7}, g_{1}\right), \\
& \left(d_{8}, g_{2}\right),\left(d_{9}, g_{3}\right),\left(d_{10}, g_{4}\right),\left(d_{11}, g_{5}\right),\left(d_{12}, g_{6}\right),\left(d_{13}, g_{7}\right),\left(d_{14}, d_{8}\right), \\
& \left(d_{9}, g_{8}\right),\left(d_{10}, g_{9}\right),\left(d_{11}, g_{10}\right),\left(d_{12}, g_{11}\right),\left(d_{13}, g_{12}\right),\left(d_{14}, g_{13}\right)
\end{aligned}
$$

ve benzer olarak 5. çember katmanındaki yıldız koordinatları;

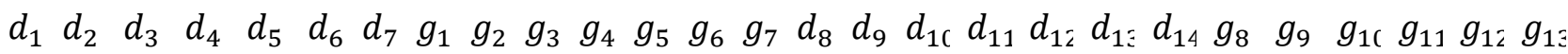

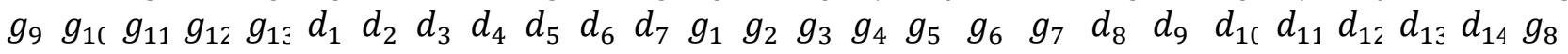

$$
\begin{aligned}
\{27 / 8\} \rightarrow & \left(d_{1}, g_{9}\right),\left(d_{2}, g_{10}\right),\left(d_{3}, g_{11}\right),\left(d_{4}, g_{12}\right),\left(d_{5}, g_{13}\right),\left(d_{6}, d_{1}\right),\left(d_{7}, d_{2}\right), \\
& \left(d_{3}, g_{1}\right),\left(d_{4}, g_{2}\right),\left(d_{5}, g_{3}\right),\left(d_{6}, g_{4}\right),\left(d_{7}, g_{5}\right),\left(g_{6}, g_{1}\right),\left(g_{7}, g_{2}\right), \\
& \left(d_{8}, g_{3}\right),\left(d_{9}, g_{4}\right),\left(d_{10}, g_{5}\right),\left(d_{11}, g_{6}\right),\left(d_{12}, g_{7}\right),\left(d_{13}, d_{8}\right),\left(d_{14}, d_{9}\right), \\
& \left(d_{10}, g_{8}\right),\left(d_{11}, g_{9}\right),\left(d_{12}, g_{10}\right),\left(d_{13}, g_{11}\right),\left(d_{14}, g_{12}\right),\left(g_{13}, g_{8}\right)
\end{aligned}
$$

şeklinde elde edilir.

\section{Tartışma ve sonuçlar}

Bu çalışma kapsamında,

- Düzgün yıldız çokgenler için yeni tanımlar ve özelliklerle beraber farklı bir çizim tekniği geliştirilmiştir.

- Düzgün yıldız çokgenleri oluşturan oluşum çizgileri yatay eksenle oluşturdukları açılara göre "dar açılı çizgi" ve "geniş açılı çizgi" şeklinde adlandırılıp önemli sonuçlar elde edilmiştir.

- Düzgün yıldız çokgen üzerinde dar ve geniş oluşum çizgilerinin yerleşim düzeni ile dar ve geniş oluşum çizgi sayısı mod 4'e göre genelleştirilmiş̧ir.

- Herhangi bir düzgün yıldız çokgende oluşum çizgilerinin kesişmesiyle oluşan noktalardan geçen çemberlere "çember katmanları" ve oluşum çizgilerinin kesişim noktalarına "yıldız koordinatlar" adı verilip özellikleri incelenmiştir.

- Herhangi bir düzgün yıldız çokgende açılarına göre oluşum çizgilerinin dizilimini ve yıldız koordinatların konumlarını şekil çizmeden belirleyebileceğimiz bağıntılar geliştirilmiştir.

- Yıldız koordinat tespiti için örnek uygulamalar yapılmıştır.

\section{Kaynaklar}

Arslan, M. ve Tuncel, Y. (2019). Battalgazi Ulu Camii ve geometrik analizler. Yeditepe Üniversitesi Tarih Bölümü Araştırma Dergisi, 2 (5), 104-123.

Bradwardine, T. (1989). Geometria Speculativa; Stuttgart: Steiner-Verl. Wiesbaden, Germany.

Coxeter, H.S.M. (1969). Introduction to Geometry, Star polygons p.36-38, 2nd ed., Wiley, New York.

Coxeter, H.S.M. (1974). Regular Complex Polytopes, Cambridge University Press, London.

Grunbaum, B. and Shephard, G. C. (1977). Tilings by Regular Polygons, Mathematics Magazine 50, 227-247 and 51, 205-206.

Khamjane, A. and Benslimane, R. (2018). A computerized method for generating slamic star patterns, Computer-Aided Design, 97, 15-26. https://doi.org/10.1016/j.cad.2017.11.002.

Kepler, J. (1997). Harmonices Mundi, Vol. 1, Gottfried Tampach, 1619; English transl., The Harmony of the World, American Philosophical Society, $\mathrm{ABD}$.

Mülayim, S. (1982). Anadolu Türk Mimarisinde Geometrik Süslemeler. Kültür Bakanlığı Yayınları, Ankara.

Wilson, R.S. (2001). Regular Star Polygons, Sonoma State University, California. (2019, 16 Aralık). Erişim adresi: http://web.sonoma.edu/users/w/wilsonst/papers/ stars/default.html 